\title{
The Formation of the Structure and Tribological Properties of Composite Bronzes Reinforced with Steel Dendrites
}

\section{Zhilyakov A.Yu. ${ }^{1}$, Khristolyubov A.S. ${ }^{2}$, Potekhin B.A. ${ }^{2}$, and Ilyushin V.V. ${ }^{2}$}

${ }^{1}$ Department of Heat Treatment and Physics of Metals, Institute of New Materials and Technologies, Ural Federal University named after the first President of Russia B.N.Yeltsin, 620002, 19 Mira Street, Ekaterinburg, Russia

${ }^{2}$ Ural State Forest Engineering University, Yekaterinburg, 620100, 36 Siberian Road, Ekaterinburg Russia

\section{Abstract}

The possibility of creating of composite bronzes reinforced with steel dendrites from martensitic, austenitic and ferritic steels was considered. Compared to the $\mathrm{BrO} 10$ bronze widely used in the sliding friction units, bronze BRZHNA 12-7-1 has an increased complex of mechanical, technological and, especially, tribological properties. At comparable

Corresponding Author:

Zhilyakov A.Yu.

a.y.zhilyakov@urfu.ru

Received: 25 February 2019

Accepted: 9 April 2019

Published: 15 April 2019

Publishing services provided by Knowledge E

(c) Zhilyakov A.Yu. et al. This article is distributed under the terms of the Creative Commons Attribution License, which permits unrestricted use and redistribution provided that the original author and source are credited.

Selection and Peer-review under the responsibility of The Ural school-seminar of metal scientists-young researchers Conference Committee.

\section{G OPEN ACCESS} values of the friction coefficient, the wear resistance of bronze BRZHNA 12-7-1 is much higher. In contrast to the classic BrO10 bronze, composite bronze can be obtained in a hot-deformed state, welded, welded on steel and cast iron.

The level of mechanical properties: $\sigma_{0.2}=220 \mathrm{MPa} ; \sigma_{u}=295 \mathrm{MPa} ; \psi=38 \%$ is $1.5-3$ times higher than that of BrO10. The possibility of creating an industrial version of composite bronze with a particularly high level of tribological properties was proved for the first time at the laboratory level.

Keywords: composite bronze, mechanical and technological properties, martensitic steel, austenitic steel, ferritic steel.

\section{Intorduction}

Tin bronzes, such as BrO10 gave a good account of itself in sliding friction units as antifriction sliding alloys. However, it cannot be deformed either in hot or cold states due to the presence in it of intermetallic compounds like Cu31Sn8. Therefore the range of their rational use limits [1]. Welding, restoration surfacing is difficult, since the intermetallic compounds are brittle at all temperatures of their existence and have an unfavorable acute-angular shape.

The technological plasticity of BrO10 bronze can be made satisfactory by dissolving and transferring coarse, brittle intermetallic compounds into $\alpha$ (Cu-Sn) solid solution. In this case, the rule of Charpie-Bochwara (for anti-friction alloys) is violated and bronze completely loses its service, that is, tribological properties. 
Our attempts to improve the morphology of intermetallic compounds using additional alloying of $\mathrm{BrO} 10$ by $\mathrm{Ni}$ and $\mathrm{Co}$ did not give positive results, and we replaced the Cu31Sn8 intermetallic compound with steel dendrites, the formation of which is known in the $\mathrm{Cu}$ - Fe alloys [2-6].

\section{Materials and Methods}

Experimental bronze ingots with a diameter of $65 \mathrm{~mm}$ and a height of $120 \mathrm{~mm}$ (weight about $2 \mathrm{~kg}$ ) were prepared by melting pure charge materials in a Tamman furnace using alundum crucibles in a reducing atmosphere of carbon monoxide.

Further, the rod ingots $7 \mathrm{~mm}$ in diameter were made by vacuum casting, the rate of their crystallization and cooling was about $700^{\circ} \mathrm{C} / \mathrm{s}$ [2]. In addition, the castings of the studied bronzes were melted down by a tungsten electrode in an argon environment to a depth of $5 \mathrm{~mm}$.

Table 1 shows the chemical composition of studied bronze.

TABLE 1: The chemical composition of the studied bronze, [wt.\%].

\begin{tabular}{l|c|c|c|c|c|c|}
\hline Bronze & $\mathbf{F e}$ & $\mathbf{N i}$ & $\mathbf{C o}$ & $\mathbf{C r}$ & $\mathbf{A l}$ & $\mathbf{S i}$ \\
\hline BrZhNKA 9-4-1-1 & 8,6 & 3,9 & 1,1 & - & 0,8 & - \\
\hline BrZhNA 12-7-1 & 12,9 & 6.0 & - & - & 1,0 & - \\
\hline BrZhNKA 23-8-3-1 & 22,9 & 82 & 2,8 & - & 1,0 & - \\
\hline BrZhNKhA 12-9-3-1 & 13,1 & 9,7 & - & 2,3 & 1,1 & - \\
\hline BrZhNKhK 12-7-5-1 & 13,4 & 7,2 & - & 5,8 & - & 1.0 \\
\hline Note: 1) Cu - the rest; 2) the amount of impurities does not exceed 0.30\%, S and P $\leq 0.02 \%$ &
\end{tabular}

A local chemical analysis was performed using Jeol JSM 6490 LV scanning electron microscope with an attachment for an energy dispersive X-ray microanalysis (Oxford Inca Dry Cool) with a resolution of $133 \mathrm{eV}$. A total chemical analysis of the alloy was performed on an area of $1 \mathrm{~mm}^{2}$ with the averaging of the results of three measurements taken at different regions. The heat treatment was performed in a SNOL 8.2/1100 chamber furnace, the deviations from the specified temperature did not exceed $\pm 5^{\circ} \mathrm{C}$.

The number of dendrites by their relative area on the surface of the metallographic section (sample) was estimated according to the method [7].

The microhardness of the structural constituents of cast and heat treated alloys were measured using PMT-3M and 402MVD devices under a load of $0.5 \mathrm{~N}$.

The mechanical characteristics of the alloy were determined using standard (fivefold) tensile specimens with a diameter of the gage part of $5 \mathrm{~mm}$ at room temperature using an Instron 3382 testing complex. 
The coefficient of friction and the rate of wear were determined using a special setup mounted on the base of a lathe tool with a numerical program control. The tests were performed using the disk-finger scheme with a continuous computer fixation of the testing parameters (pressure, rate of sliding, temperature). In each experiment, three specimens with dimensions of $6 \times 6 \times 12 \mathrm{~mm}$ were used; a disk made of steel ShKh15 (45 HRC) was used as a counterbody. The test procedure has been described in [8].

\section{Results and Discussion}

The low solubility of $\mathrm{Fe}$ and $\mathrm{Co}$ in $\mathrm{Cu}$ in the solid state: 1.92 and 3.5 at.\% at $950^{\circ} \mathrm{C}$ and less than 0.5 at.\% at $600^{\circ} \mathrm{C}$, respectively, determines the formation of dendrites in the process of crystallization, the basis of which are $\mathrm{Fe}, \mathrm{Ni}$ and $\mathrm{Co}$. The crystallization of iron dendrites begins at temperatures of about $1250^{\circ} \mathrm{C}$, at which temperature the solubility of $\mathrm{Cu}$ in $\mathrm{\gamma Fe}$ is up to 10 at.\% [9].

The size of dendrites in casting ingots weighing $3 \mathrm{~kg}$ is 15-20 microns (Fig. 1, a). With a high rate of crystallization and cooling of the melt $\left(700^{\circ} \mathrm{C} / \mathrm{s}\right)$, their size decreases by an order of magnitude, while steel dendrites, unlike intermetallics such as Cu31Sn8, have a favorable shape, which, as a rule, affects mechanical and technological properties.

First of all the quantity (volume) of dendrites depends on the content of iron in bronze, and the additional alloying of alloys by $\mathrm{Ni}, \mathrm{Co}, \mathrm{Al}$, and others forms carbon-free steels of different classes. Figure 2a shows the linear dependence of the number of dendrites on the total content of $\mathrm{Fe}, \mathrm{Ni}, \mathrm{Co}$. in bronze.

The composition of dendrites is presented in the diagram (Fig. 2, b), from which it follows that the amount of $\mathrm{Fe}$ in them is almost always the same and is $58-62 \%$, the copper content is also stable and is $19-23 \%$, and the content of $\mathrm{Ni}$ and $\mathrm{Co}$ is proportional to their number in the charge.

During the bronzes cooling after crystallization zones enriched in $\mathrm{Cu}, \mathrm{Ni}$, and $\mathrm{Co}$ are formed due to a decrease in the copper solubility in iron dendrites [10-13]. These zones (inclusions) are close in chemical composition to the matrix and are in the form of plates that coagulate after heating to $450^{\circ} \mathrm{C}$ and holding at this temperature for 2 hours (Fig. $3, a, b)$. In other cases, these precipitates are shells around the grains that create the dendrite; a shell structure is formed (Fig. 3, c) [14-15].

The transverse size of all these inclusions is $<0.2 \mu \mathrm{m}$. Whereas these areas are a substitution solid solution of $\mathrm{Ni}, \mathrm{Al}$ in copper and are close in composition to the matrix. 


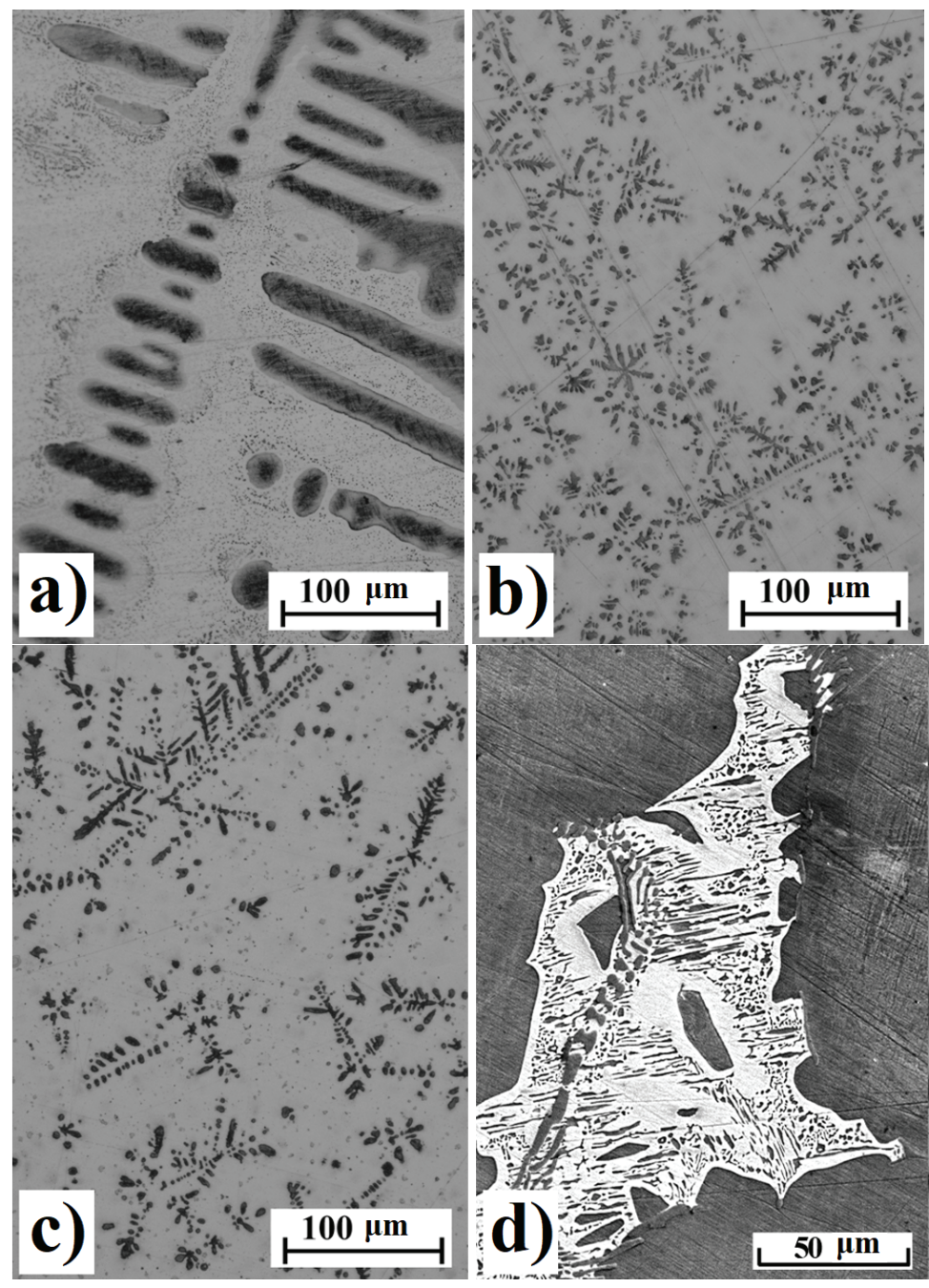

Figure 1: Morphological features of the structure of composite bronze BRZHNA 12-7-1, depending on the technology of its manufacture: a) casting $3 \mathrm{~kg}$; b) vacuum casting; c) arc remelting in argon; d) casting bronze $\mathrm{BrO10.}$

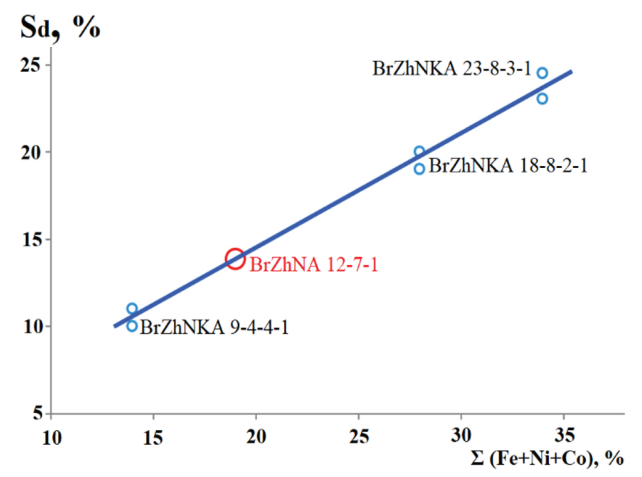

a)

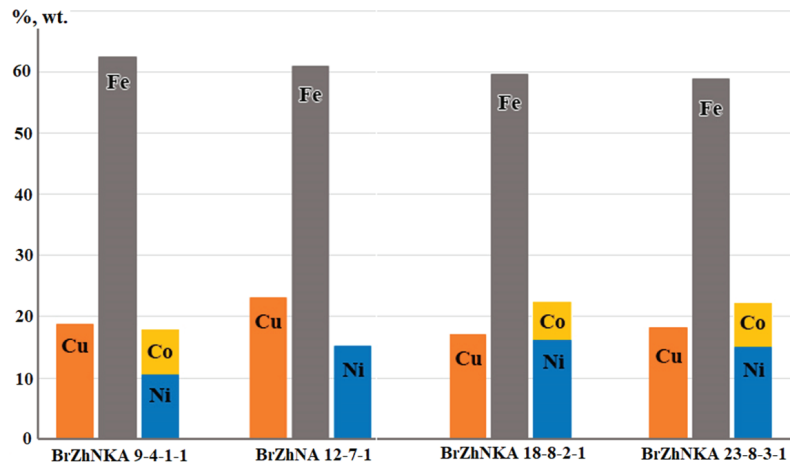

b)

Figure 2: The dependence of the number of dendrites $\left(\mathrm{S}_{d}\right)$ - a) andtheir chemical composition in bronze b).

For example, in bronze BRZhNA 12-7-1, the composition of the "steel" part of the dendrite is H15U1 steel, and the matrix and inclusions in the dendrites are bronze BrZhN 3-3 [16]. 


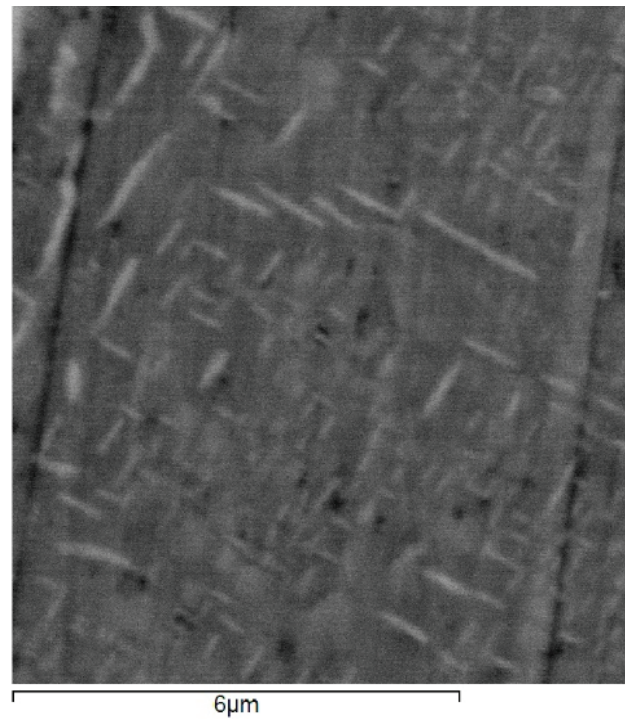

a)

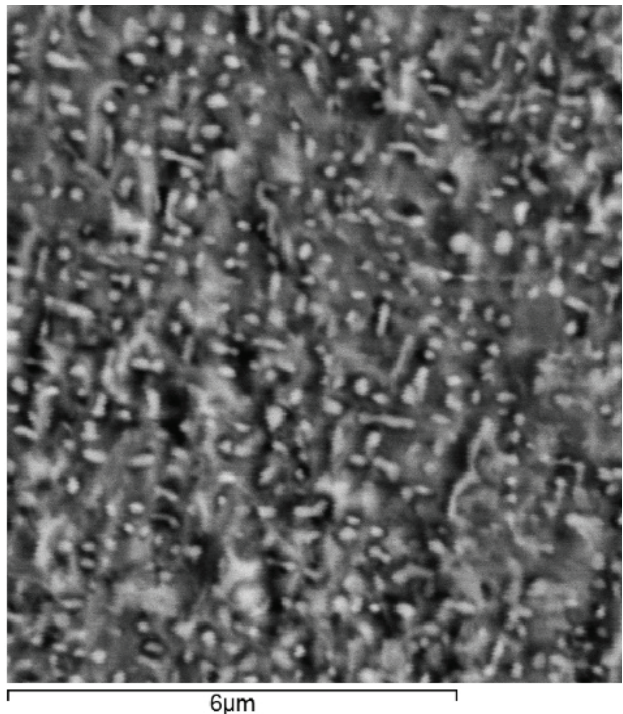

b)

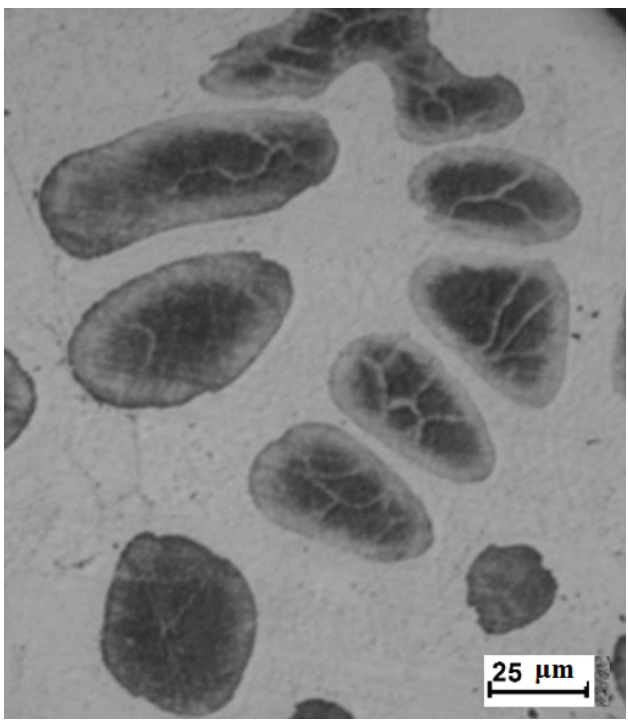

c)

Figure 3: The internal structure of the dendrite in bronze BRZHNKA 9-4-1-1 (a - casting, b- after aging $450^{\circ}$ C for 2 hours) and BrZhNKA 23-8-3-1 (c - casting).

The experimental data presented in Table 2 show that the hardness of the base surface (steel dendrites, intermetallic in BrO10) does not affect the coefficient of friction and is in the range of $0.013-0.018$, and the wear resistance varies widely from 0.001 to $0.025 \mu \mathrm{m} / \mathrm{km}$.

Whereas the wear resistance determines the reliability and durability of friction-slip units. In our opinion, the reason for high wear resistance is that steel dendrites (Fig. 3) have soft inclusions, and there are dispersed solid steel inclusions in the matrix [20, 22]. In the process of tribological testing, the hydraulic effect of the lubricant forms an oil-intensive microrelief on the friction-slip surface, which provides very high wear 
TABLE 2: The dependence of friction coefficient (f) and wear rate (I) of the studied bronzes on the dendrite structure and hardness.

\begin{tabular}{|c|c|}
\hline $\mathbf{N}^{\circ}$ & $\begin{array}{l}\text { The composition of bronze, } \\
\text { castings }\end{array}$ \\
\hline 1 & $\mathrm{BrO10}$ \\
\hline 2 & BrZhNA 12-7-1 \\
\hline 3 & BrZhNKhA 12-9-3-1 \\
\hline 4 & BrZhNKhK 12-7-5-1 \\
\hline 5 & BrZhNA 12-7-1 vacuum casting \\
\hline 6 & BrZhNA 12-7-1 arc remelting \\
\hline 7 & $\begin{array}{l}\text { BrZhNKhK 12-7-5-1 vacuum } \\
\text { casting }\end{array}$ \\
\hline
\end{tabular}

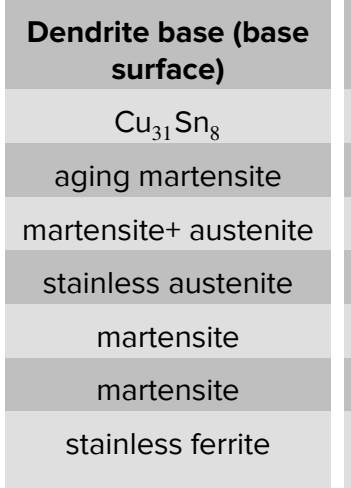

\begin{tabular}{|c|c|c|}
\hline $\mathbf{H V}^{50}$ & $\mathbf{f}_{m p}$ & $\mathbf{I},[\boldsymbol{\mu m} / \mathbf{k m}]$ \\
\hline 401 & 0,016 & 0,025 \\
\hline 338 & 0,018 & 0,026 \\
\hline 200 & 0,015 & 0,010 \\
\hline 189 & 0,013 & 0,006 \\
\hline- & 0,017 & 0,002 \\
\hline- & 0,017 & 0,002 \\
\hline- & 0,016 & 0,001 \\
\hline
\end{tabular}

Note: 1) positions $1-4$ - castings weighing $3 \mathrm{~kg}$, positions 5-7 - rods $7 \mathrm{~mm}$ in diameter, length 600 $\mathrm{mm}$, obtained by vacuum casting; 2 ) the microhardness of dendrites in bronze (positions 5-7) is not determined due to their high dispersion, but, in our opinion, cannot be higher than 200 HV50; 3) the microhardness of the matrix for different bronzes is in the range of 100-120 HV50 4) the friction coefficient is determined at $P=3 \mathrm{MPa}$ and $\mathrm{V}=3.3 \mathrm{~m} / \mathrm{s}$.

resistance of composite bronzes, especially in the dispersed state (positions 5-6, Table 2).

Composite bronze BrZhNKhK 12-7-5-1 has a particularly high wear resistance (position 7, table 2) in which the dendrites are stainless steel with the composition Kh23N15S1, "coated" with solid oxides of the $(\mathrm{Fe}, \mathrm{Cr})_{2} \mathrm{O}_{3}$ type.

The mechanical properties of composite bronze BrZhNA 12-7-1 are significantly higher than those of $\mathrm{BrO10}$ bronze, especially in terms of plastic properties, even in casting without any heat treatment (position 2, Table 3).

TABLE 3: Mechanical properties of composite bronze BrZhNA 12-7-1 after various treatments.
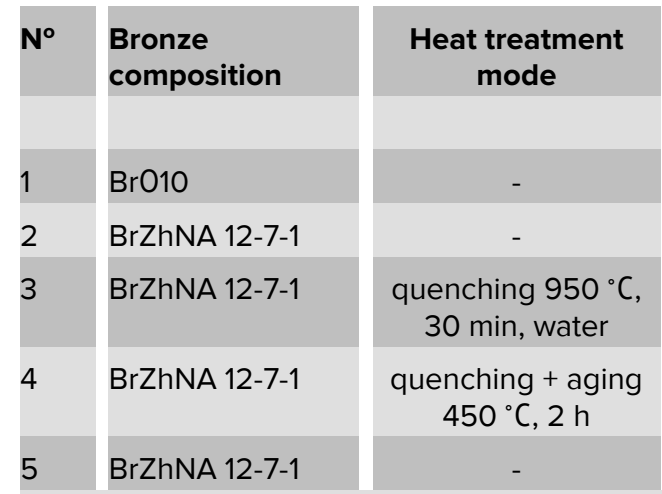

\begin{tabular}{|c|c|c|c|c|}
\multicolumn{5}{|c|}{ Mechanical properties } \\
\hline$\sigma_{0,2},[\mathrm{MPa}]$ & $\sigma_{u},[\mathrm{MPa}]$ & $\psi,[\%]$ & $\delta,[\%]$ & $\delta_{t},[\%]$ \\
\hline 170 & 215 & $10-14$ & $3-10$ & $<1$ \\
\hline 170 & 364 & 42,8 & 38,2 & 20,3 \\
\hline 147 & 300 & 69,5 & 66,9 & 34,2 \\
\hline 149 & 301 & 39,4 & 51,4 & 39,3 \\
\hline 220 & 295 & 38,5 & 16,0 & 6,4 \\
\hline
\end{tabular}

Note: Positions 1-4 ingots weighing $3 \mathrm{~kg}$, diameter $50 \mathrm{~mm}$; Position 5 - rod $7 \mathrm{~mm}$ in diameter, obtained by vacuum casting.

In addition, unlike BrO10 bronze, widely used in mechanical engineering, composite bronze is well surfaced on steel and cast iron, more environmentally friendly (no tin) [22]. 


\section{Conclusions}

At the laboratory level the studies substantiate the reasonability of creating an industrial version of composite bronze with particularly high wear resistance under conditions of sliding friction.

The increased level of mechanical and technological properties makes it possible to use composite bronzes reinforced with dendrites from steels of different classes, both in cast and hot-deformed states, that is, to expand the range of their use in comparison with the "prototype" BrO10 bronze. BRZHNA 12-7-1 bronze was shown to be the best version of such bronze.

\section{References}

[1] B.N. Arzamasov Construction materials: a Handbook. Mechanical Engineering, Moscow, 1990.

[2] Yu.S. Avraamov, A.D. Shlyapin Alloys based on systems with limited solubility in the liquid state. Intercontact science, Moscow, 2002

[3] C.P. Wang, X.J. Liu, I. Ohnuma, R. Kainuma, K. Ishida Thermodynamic database of the phase diagrams in Cu-Fe base ternary systems. J. Phase Equilib. Diffus. 25 (2004) 320-328.

[4] M. Baricco, E. Bosco, G. Acconciaioco, P. Rizzi, M. Coisson Rapid solidification of CuFe-Ni alloys. Mater. Sci. Eng. A. 375-377 (2004) 1019-1023.

[5] Y.Y. Chuang, R. Schmid, and Y.A. Chang Calculation of the equilibrium phase diagrams and the spinodally decomposed structures of the Fe-Cu-Ni system. Acta Mater. 8 (1985) 1369-1380.

[6] K.P. Gupta The Cu-Fe-Ni (Copper-Iron-Nickel) system. Phase Diagram of Ternary Nickel Alloys. 1 (1990) 290-315.

[7] S.A. Saltykov Stereometric metallography. Metallurgy, Moscow, 1970.

[8] B.A. Potekhin, V.V. Ilyushin, A.S. Khristolyubov Special properties of babbitt B83 obtained by the turbulent casting method. Casting and metallurgy. 57 (2010) 78-81.

[9] N.P. Lyakishev State diagrams of double metal systems: A Handbook. Mashinostroenie, Moscow, 1997

[10] G.W. Qin, G. Zhao, M. Jiang, H.X. Li, S.M. Hao. The isothermal sections of the $\mathrm{Cu}-\mathrm{Ni}-$ Fe ternary system at $600,800,1000$, and $1050^{\circ} \mathrm{C}$. Z. Metallkd. 5 (2000) 379-382.

[11] V.M. Lopez, N. Sano, T. Sakurai, and K. Hirano. A study of phase decomposition in Cu-Ni-Fe alloys. Acta Metall. Mat. 1 (1993) 265-271. 
[12] K.J. Ronka, A.A. Kodentsov, P.J.J. Van Loon, J.K. Kivilahti, F.J.J. Van Loo. Thermodynamic and kinetic study of diffusion paths in the system $\mathrm{Cu}-\mathrm{Fe}-\mathrm{Ni}$. Metall. Mater. Trans. A. 27 (1996) 2229-2238.

[13] . U. Ugaste, A.A. Kodentsov, and F.J.J. Van Loo. Interdiffusion and Kirkendall-effect in the Fe-Ni-Cu system. Sol. St. Phenomena. 72 (2000) 117-122.

[14] B. Potekhin, A. Hernández, A. Khristolyubov, V. Ilushin. Formación de la estructura y propiedades de los bronces Fe-Ni-AI. CIM 2011 - VI Congreso Internacional del Materiales. 27-30 Noviembre de 2011, Bogotá D.C., Colombia.

[15] B.A. Potekhin, V.V. Ilyushin, A.S. Khristolyubov, A.Yu. Zhilyakov, A. Hernandez. The possibility of creating a composite bronze alloy - martensitic-aging steel. MITOM. 5 (2013) 6-10.

[16] B.A. Potekhin, A.S. Khristolyubov, A.Yu. Zhilyakov, V.V. Ilyushin. Features of the formation of the structure of composite bronzes reinforced with steel dendrites. Voprosy Materialovedenia. 76 (2013) 43-49.

[17] Ya.M. Potak. High-strength steels. Metallurgy, Moscow, 1972.

[18] Ya.M. Potak, and E.A. Sagalevich. Structural Diagram of Deformable Stainless Steels. MITOM. 9 (1971) 12-16.

[19] E.A. Matsin. Charpy rule and antifriction alloy surface microrelief. Proceedings of the 2nd All-Union Conference on Friction and Wear in Machines. Academy of Sciences of the USSR, Moscow. 3 (1948) 222-229.

[20] B.A. Potekhin, V.V. Ilyushin, A.S. Khristolyubov, and A.Yu. Zhilyakov. Formation of structure and properties of composite bronzes reinforced by steel dendrites. Phys. Met. Metallogr. 115 (2014) 413-419.

[22] B.A. Potekhin, A.S. Khristolyubov, A.A. Hernandez Fereira. New class of composite bronze, armed with steel dendrites for antifriction technique. XXIV International scientific conference Trans \& Motauto 16, Varna Bulgaria, June 2016.

[22] V.I. Shumyakov, B.A. Potekhin, Yu.S. Korobov, A.S. Khristolyubov, V.V. Ilyushin, S.P. Kochugov, A.N. Balin, and A.A. Vishnevskii, RF Patent 170923, (2017). 